\title{
Dynamic Compressive Properties of 2D-C/SiC Composites under Low Temperature
}

\author{
Z. B. TANG ${ }^{a}{ }^{*}$, Q. DENG ${ }^{b}$, L.H. YE ${ }^{c}$ and P. XUE ${ }^{d}$ \\ School of Aeronautics, Northwestern Ploytechnical University, Xi'an, Shaanxi, 710072, China \\ atangzhongbin@nwpu.edu.cn, 'dengqiong24@nwpu.edu.cn, cxiaohai880513@126.com, \\ dp.xue@nwpu.edu.cn \\ *Corresponding author: tangzhongbin@nwpu.edu.cn
}

\begin{abstract}
Keywords: Ceramic Matrix Composites (CMCs), SHPB; Low Temperature, Dynamic Compressive Properties.
\end{abstract}

\begin{abstract}
The dynamic compressive experiments of 2D-C/SiC composites under low temperature were performed on the SHPB system. The low temperatures at $173 \mathrm{~K}$ and $103 \mathrm{~K}$ were obtained by controlling the ratio of the absolute alcohol to the liquid nitrogen. The wave shapers were designed to meet the requirements of stress uniformity and constant strain rate in SHPB setup. The experimental results show that the 2D-C/SiC composites exhibit pseudo-plastic behaviors under dynamic loading and low temperature conditions for the micro cracks in the composite. The significant strain softening of the specimens occurred instead of the typical brittle failure when the stress exceeded the compressive strength in the test, and the specimens have experienced a large deformation before the final failure. The dynamic compressive strength of the composites increased with decrease of temperature, however the failure strain decreased. The strength of the interface between internal fibers and matrix in the 2D-C/SiC composites enhanced at low temperatures, resulting in the higher compressive strength of the composites.
\end{abstract}

\section{Introduction}

$\mathrm{C} / \mathrm{SiC}$ composites have been widely used as the outside thermal protection structures of aerospace vehicles for its low density and high anti-thermal shocking properties ${ }^{[1-3]}$. The thermal protection structures in service are always threatened by the increase in space debris. If the anti-thermal structures are damaged by the high velocity impact, the primary structures of aerospace vehicles will be destroyed by ultrahigh temperature when returning from the space. In order to predict the impact of the debris at ultrahigh velocity on the $\mathrm{C} / \mathrm{SiC}$ structure, dynamic compressive properties at low temperature is desired.

From literature, studies on mechanical properties of $\mathrm{C} / \mathrm{SiC}$ composites are concentrated on static properties. Jiao et al ${ }^{[4-8]}$ obtained the static properties of $\mathrm{C} / \mathrm{SiC}$ composites by tension, compression and shear experiments. The deformation mechanism and failure models of $\mathrm{C} / \mathrm{SiC}$ composites have been analyzed. The results show a good linear relationship between the compressive stress and strain. The angle between the fractured face of the specimen and loading direction is $13^{\circ}$, and interface failure is a main failure mode. Garland et al ${ }^{[9]}$ investigated the effect of the properties of the interface between the reinforced fibers and matrix with the damage development. He found the magnitude of the damage angle is depended on the strength of the interface. Narayanan and Schadler ${ }^{[10]}$ also discussed the relationship between the damage angle and the compressive strength of the composites. They found that the magnitude of the damage angle increased with the increase of the compressive strength. Yotte and Quenisse ${ }^{[11]}$ concluded that the nonlinear properties of 2D-C/SiC exhibit pseudo-plastic mechanical behaviors, because there were lots of internal micro cracks in the composite material. The stress concentration occurred around the initial micro cracks during the loading procedure. However, the stress concentration can not be released under high loading rate, thus the damage evolvement was accelerated and the failure strain decreased.

In this study, the dynamic mechanical properties of $2 \mathrm{D}-\mathrm{C} / \mathrm{SiC}$ composites under low temperature are investigated. The dynamic compressive experiments of these composites were performed by the 
SHPB system. The testing temperature was from $173 \mathrm{~K}$ and $103 \mathrm{~K}$ and the strain rate was $1000 \mathrm{~s}^{-1}$.

\section{Experimental Method}

\section{Specimen}

The 2D-C/SiC composite specimens were made by the Science and Technology on Thermostructural Composite Material Laboratory in Northwest Polytechnical University. The carbon fibers (T300-1K, made by Nippon Toray Corporation) were firstly woven into carbon lamina with $0.16 \mathrm{~mm}$ thickness, and then the carbon laminas were prefabricated to panel in $0^{\circ} / 90^{\circ}$ direction. The PyC layer with 100-200nm thickness was deposited on the surface of the fibers, and the SiC matrix was deposited by the CVI technology. The volume percentage of the fibers was $45 \%$ and the porosity of $2 \mathrm{D}-\mathrm{C} / \mathrm{SiC}$ composites was $5 \% \sim 8 \%$. Finally, the $2 \mathrm{D}-\mathrm{C} / \mathrm{SiC}$ plate was cut into test cubes by the diamond.

The specimens' dimension is $4 \mathrm{~mm} \times 4 \mathrm{~mm} \times 3 \mathrm{~mm}$ approximately. Figure 1 shows the structure of 2D-C/SiC composites and the loading direction in test.

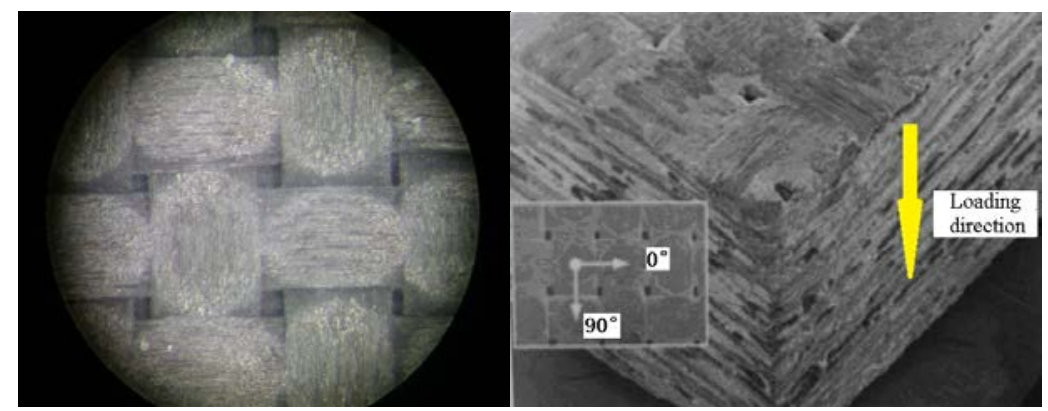

Figure1 The structure of the 2D-C/SiC

\section{Experiments}

The compressive experiments were performed using SHPB system. The shape and the size of the wave shapers were designed to meet constant strain-rate loading. The low temperatures of $173 \mathrm{~K}$ and $103 \mathrm{~K}$ were obtained by controlling the ratio of absolute alcohol to liquid nitrogen. The incident wave, reflection wave and the transmission wave were measured by the strain gages glued on the surface of the bars. The stress, strain and the strain rate of the specimen can be calculated by the following equations.

$$
\left\{\begin{array}{l}
\sigma(t)=\frac{\mathrm{EA}}{\mathrm{A}_{0}} \varepsilon_{t} \\
\varepsilon(t)=-\frac{2 c}{l_{0}} \int_{0}^{t} \varepsilon_{r} d t \\
\varepsilon(t)=-\frac{2 c}{l_{0}} \varepsilon_{r}
\end{array}\right.
$$

where $\mathrm{E}$ is elastic modulus of the bar material. $\mathrm{A}$ is the cross section area of the bar; $l_{0}$ and $\mathrm{A}_{0}$ are the thickness and the cross section area of the specimen. $c=\sqrt{E / \rho}$ is the stress wave velocity of the elastic bar.

The temperature of the specimen is measured by a thermocouple in the heat preservation. Figure 2 shows the time histories of the temperature of the specimens. The temperatures dropped to the aimed temperature of $173 \mathrm{~K}$ and $103 \mathrm{~K}$ in five minutes by the mixture of the absolute alcohol and liquid nitrogen. The temperature fluctuation is caused by the instability of the volatilization of the liquid nitrogen. The temperature fluctuation was within a range of $\pm 10 \mathrm{~K}$ by controlling the flow rate of the liquid mixture with temperature controller. Before the test, all the specimens were set at the temperature of $173 \mathrm{~K}$ or $103 \mathrm{~K}$ for heat preservation for 15 minutes. 


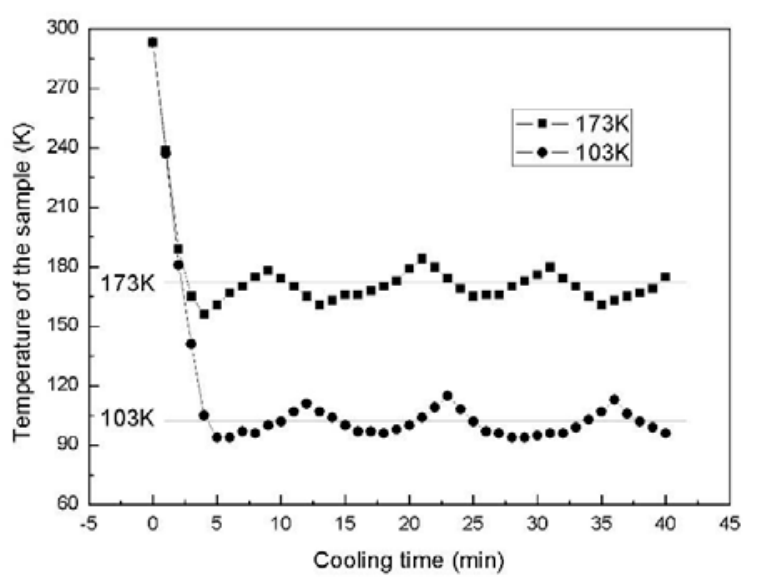

Figure 2 The time history of the temperature of the specimen when cooling

\section{Results and discussion}

The failure strain of the ceramic matrix composites is much smaller that of the elastic-plastic metal, though the fracture toughness of the composites has been enhanced by the fibers. In the traditional SPHB experiments, the rising time of the loading wave is in the range of $10 \sim 20 \mu \mathrm{s}$. For the low impedance material, the wave velocity of it is too low to obtain the stress equilibrium during the impulse rising time. For loading at high strain rate, the specimen was fractured, or failed at the location of the maximum impulse oscillation. It is necessary to analyze the stress equilibrium of the specimen at high strain rate loading. Usually, the stress uniform coefficient $\alpha(t)$ is introduced to estimate the stress equilibrium in SPHB experiments as following

$$
\alpha(t)=\frac{\left|\sigma_{1}(t)-\sigma_{2}(t)\right|}{\left|\sigma_{1}(t)+\sigma_{2}(t)\right| / 2}
$$

where, $\sigma_{1}(t)$ and $\sigma_{2}(t)$ are the stress on the contact surface of the incident bar and the transmission bar respectively.

The incident wave was approximately a triangle wave. The rise time of the incident wave had been extended and the stress equilibrium of the specimen was obtained. The stress equilibrium was obtained at the time of $6 \mu \mathrm{s}$, and the stress in the specimen was about $80 \mathrm{MPa}$. Then the stress uniform coefficient was less than $5 \%$ up to the specimen failure. The dynamic compressive stress at the strain rate of $1000 / \mathrm{s}$ for the $2 \mathrm{D}-\mathrm{C} / \mathrm{SiC}$ composites at $103 \mathrm{~K}$ and $173 \mathrm{~K}$ were obtained by using the SHPB with wave shaper. The stress equilibrium of the specimen was obtained at the strain of $0.02 \%$.

Figure 3 shows the true strain-stress curves of the specimen at the temperature of $173 \mathrm{~K}$ and $103 \mathrm{~K}$ respectively. The strain-stress curves of the dynamic compressive property exhibits significant nonlinear characteristics. The nonlinear exhibition of $2 \mathrm{D}-\mathrm{C} / \mathrm{SiC}$ was due to the pseudo-plastic mechanical behaviors of the ceramic matrix composites ${ }^{[11]}$. There were lots of internal micro defects in the initial composite material, which were the source of the micro cracks. Under dynamic loading, the stress concentrations were caused at the micro defects area, which would developed the micro cracks and damages in internal of the composites. Then the material exhibited the nonlinear characteristics by the slowly damage evolution. As in Figure 8, the typical brittle failure did not happened in the compressive experiments at the strain rate of $1000 / \mathrm{s}$. The significant strain softening of the specimens occurred when the stress had exceeded the compressive strength in the test. It is all found that the specimens experienced a large deformation before the final failure. When the temperature decreased from $173 \mathrm{~K}$ to103K, the dynamic compressive strength of the composites increased from 185Mpa to 197Mpa, but the failure strain decreased from 5\% to $3 \%$. 


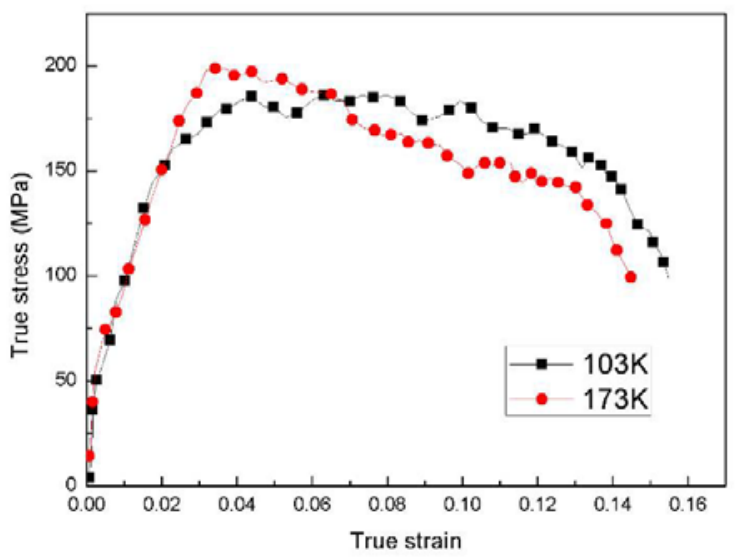

Figure 3 The dynamic true stress vs strain curves of the 2D-C/SiC (strain rate of 1000/s).

For the material with the high porosity, the pore media can be compacted under compressive loading. This is the reason why the compressive strain of the $2 \mathrm{D}-\mathrm{C} / \mathrm{SiC}$ in Z-direction was tenfold higher than that of it in fiber direction. The compressive failure strain of this composite in fiber direction was only $0.35 \%{ }^{[4]}$.

The coefficient of thermal expansion of the carbon fiber and the SiC matrix are different. The shrinkage of the carbon fiber is larger than that of the $\mathrm{SiC}$ matrix under low temperature. Carbon fiber is anisotropic material, which has two coefficients of thermal expansion in the vertical and horizontal direction. The SiC matrix made by CVI technology is the isotropic material with only one coefficients of thermal expansion. Furthermore, the coefficients of thermal expansion of the carbon fiber and the SiC matrix are mismatch with each other. Thus the residual stress between the fiber and matrix can not be avoided. The fiber expends along the radial direction when the temperature decreases, but it is restricted by matrix in the $\mathrm{C} / \mathrm{SiC}$ composites. Then the frictional force between the fiber and the matrix enhances. Thus, the compressive strength of the composites increases at low temperature for the enhanced interface strength between the fiber and matrix. It is known that the higher interface strength leads to the higher compressive strength of the composite and the fiber crushing ${ }^{[12]}$, and vice versa. Under the dynamic compressive loading, the cracks appeared in brittle matrix first. When the cracks which are perpendicular to the fiber direction develop to the weak interface, the propagation direction of them change and the cracks travel along the interface. For the strong interface, the directions of the cracks are difficult to be changed, and the cracks will penetrate the fibers, which can increase the compressive strength. As shown in Figure 4, when the fibers is expending along the radial direction at low temperature, parts of fibers are debonding with the matrix, and the interface force decrease. However, the interface frictional force is enhanced by the extrusion of the expended fibers and the matrix. Finally the compressive strength increase by the interaction of the debonding and extrusion between the fibers and matrix.

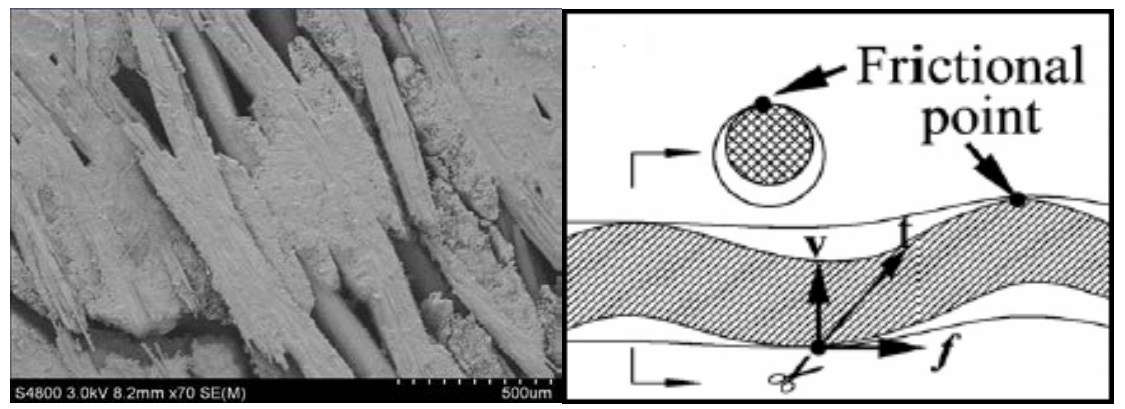

Figure 4 The schematic of composite material interface in low temperature. 


\section{Conclusions}

The dynamic compressive properties of 2D-C/SiC composites under low temperatures are performed by SHPB system. It is found that the composite exhibits the pseudo-plastic behaviors due to internal micro cracks in the initial composite material. The typical brittle failure did not happened in the compressive experiments and the significant strain softening of the specimens occurred when the stress had exceeded the compressive strength in the test. When the temperature decreased from $173 \mathrm{~K}$ to103K, the dynamic compressive strength of the composites increased from 185Mpa to 197Mpa, but the failure strain decreased from 5\% to 3\%. The interface forces between the fibers and the matrix are enhanced under low temperature, which leads to the dynamic compressive strength of the $2 \mathrm{D}-\mathrm{C} / \mathrm{SiC}$ composites.

\section{Acknowledgement}

Project supported by the National Natural Science Foundation of China (Grant Nos. 11102168, 11272267 and 51205377), Ph.D. Programs Foundation of Ministry of Education of China and 111Project (Grant No. B07050) of Northwestern Polytechnical University.

\section{References}

[1] Y. Z. Yang, J. L. Yang, D. N. Fang: 'Hypersonic vehicle thermal protection materials and structures research’, Applied Mathematics and Mechanics, 2008, 29(1), 47-56.

[2] L. T. Zhang, L. F. Cheng: 'Continuous fiber reinforced ceramic matrix composites Sustainable Development Strategy’, Acta Materiae Compositae Sinica, 2007, 24(2), 1-6.

[3] C. A. Weeks, C. T. Sun: 'Modeling non-linear rate-dependent behavior in fiber-reinforced composites’, Composites Science and Technology, 1998, 53(3/4): 603-611.

[4] G. Y. Guan, G. Q. Jiao, Z. G. Zhang: 'Uniaxial macro-mechanical property and failure mode of a 2D-woven C/SiC composite’, Acta Materiae Compositae Sinica, 2005, 22(4): 81-85.

[5] W. Xiong, G. Q. Jiao, H. X. Liu: 'Fracture toughness of plain woven C/SiC composites', Journal of the Chinese ceramic society, 2008, 36(8): 1057-1061.

[6] W. G. Pan, G. Q. Jiao, G. Y. Guan: 'Damage analysis of plain weave carbon fiber/silicon carbide ceramic matrix composites', Journal of the Chinese ceramic society, 2005, 33(11): 1321-1325.

[7] Y. J. Chang, G.Q. Jiao, Y.Q. Tao, B. Wang: 'Damage Behavior of 2.5-C/SiC Composite under Tensile Loading', Journal of Inorganic Materials, 2008, 23(3): 509-514.

[8] W. G. Pan, G. Q. Jiao, G. Y. Guan, B. Wang: 'Tensile damage behavior of three-dimensional braided C/SiC composites’, Journal of the Chinese ceramic society, 2005, 33(2): 160-163.

[9] B. D. Garland, I. J. Beyerlein, S. L. Schadler: 'The development of compression damage zones in fibrous composites’, Compos. Sci. Technol., 2001, 61 (16): 2461-80.

[10] S. Narayanan, L. S. Schadler: 'Assessment of strains along fiber surface features in graphite/epoxy composites loaded in compression’, Composites Science and Technology, 1999, 56, 1589-1596.

[11] S. Yotte, J. M. Quenisset: 'Toughness characterization of damageable ceramic matrix composites’, COMPOSITES, 1999, A (30), 191-201.

[12] M. S. Madhukar, L. T. Drzal: 'Fiber matrix adhesion and its effect on composites mechanical properties: Longitudinally $\left(0^{\circ}\right)$ compressive properties of graphite/epoxy composites’, Journal of Composite Materials, 1992, 26, 310-333. 